\title{
RESEARCH
}

Open Access

\section{Assessing patients' characteristics and treatment patterns among children with atopic dermatitis}

Davide Geat ${ }^{1 \dagger}$, Mattia Giovannini ${ }^{2 \dagger}$, Gabriele Barlocco ${ }^{3}$, Riccardo Pertile ${ }^{4}$, Manuela Pace ${ }^{5}$, Francesca Mori ${ }^{2}$, Elio Novembre ${ }^{2}$ Giampiero Girolomoni ${ }^{1}$, Mario Cristofolini ${ }^{3}$ and Ermanno Baldo ${ }^{3 *}$

\begin{abstract}
Background: Atopic dermatitis (AD) is the most common immune-mediated skin disease in childhood. Several treatment options for pediatric AD, both topical and systemic, are currently available. We carried out a single-center observational study with the aim of describing characteristics and treatment patterns in pediatric AD patients.

Methods: The study included 867 patients aged $\leq 16$ years (females $50.5 \%$, mean patient's age 5.9 years, standard deviation \pm 3.6 years) with a previous doctor-confirmed diagnosis of AD who underwent balneotherapy at the Comano Thermal Spring Water Center (Comano, Trentino, Italy) from April to October 2014.

Results: Among the patients included in the study, 41.2\% had mild (SCORing Atopic Dermatitis, SCORAD 0-15), $43.6 \%$ moderate (SCORAD 16-40) and $15.2 \%$ severe AD (SCORAD > 40). A higher occurrence of reported food allergy was observed among children with more severe $A D(p<0.0001)$, while no association was found between $\mathrm{AD}$ severity and reported inhalant allergy or passive smoking ( $p=0.15$ and 0.92 , respectively). Emollients (55.1\%) and topical corticosteroids (TCS; 45.7\%) were the main treatment options used in the previous month. The use of oral steroids and topical calcineurin inhibitors (TCI) was considerably less common (6.3 and 4.5\%, respectively), while no patients were on systemic agents other than steroids. Among patients with severe AD, $9.8 \%$ had not used TCS, $\mathrm{TCl}$ or any systemic treatments. Moreover, $20.0 \%$ of the patients in the study population had followed elimination diets, although only $27.2 \%$ of them had a reported food allergy.

Conclusions: A significant difference in the prevalence of reported food allergy emerged across the different AD severity categories. Furthermore, although further data are necessary to confirm our findings, undertreatment in children with $\mathrm{AD}$ appeared to be very common, at least among those attending the Comano Thermal Spring Water Center. Moreover, many patients followed elimination diets in the absence of reported food allergy.
\end{abstract}

Keywords: Atopic dermatitis, Comano thermal spring water, Emollients, Food allergy, Children

\footnotetext{
* Correspondence: ermanno@baldo.tn.it

${ }^{\dagger}$ Davide Geat and Mattia Giovannini joint first coauthors.

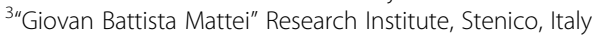

Full list of author information is available at the end of the article
}

(c) The Author(s). 2021 Open Access This article is licensed under a Creative Commons Attribution 4.0 International License, which permits use, sharing, adaptation, distribution and reproduction in any medium or format, as long as you give appropriate credit to the original author(s) and the source, provide a link to the Creative Commons licence, and indicate if changes were made. The images or other third party material in this article are included in the article's Creative Commons licence, unless indicated otherwise in a credit line to the material. If material is not included in the article's Creative Commons licence and your intended use is not permitted by statutory regulation or exceeds the permitted use, you will need to obtain permission directly from the copyright holder. To view a copy of this licence, visit http://creativecommons.org/licenses/by/4.0/. The Creative Commons Public Domain Dedication waiver (http://creativecommons.org/publicdomain/zero/1.0/) applies to the data made available in this article, unless otherwise stated in a credit line to the data. 


\section{Introduction}

Atopic dermatitis (AD) is the most common chronic immune-mediate skin disease in childhood, with a lifetime prevalence ranging between 15 and 20\% [1]. Because of its clinical manifestations and its association with psychological stress, sleeping disturbances and poor performance at school, the impact of AD on children's quality of life is considerable [2]. Topical treatments are the main management options for mild to severe AD in children. They include emollients, topical corticosteroids (TCS), topical calcineurin inhibitors (TCI) and, currently, crisaborole, which is mostly used in the United States. Emollients play a crucial role, as they contribute to restore the skin barrier, whose anomalies are a driving factor for $\mathrm{AD}$. In fact, decreased function of the skin barrier due to genetic (e.g., filaggrin deficiency) or acquired factors can lead both to increased allergen penetration and easier skin irritation, which contribute to skin inflammation in AD. On the other hand, TCS exert an anti-inflammatory function that is crucial to control the acute flares of the disease [3]. Moreover, an intermittent use of TCS on skin sites where AD tends to recur (i.e., proactive therapy) can reduce the number of relapses [4]. However, despite their efficacy, adherence to TCS is often suboptimal because of the anxiety and fears of patients and their caregivers [5, 6]. "Corticosteroid phobia" was the subject of a recent systematic review that included 16 studies and reported a prevalence ranging between 21.0 and $83.7 \%$ worldwide [7]. This phenomenon is rooted in patients' irrational fears of TCS-triggered skin side effects [8, 9]. Finally, severe AD in children and adolescents can also be treated with several systemic options including steroids, cyclosporin and dupilumab $[3,10]$.

\section{Methods}

We carried out a single-center observational study with the aim of describing patients' characteristics and treatment patterns among Italian pediatric patients with AD. The study was conducted at the Comano Thermal Spring Water Center (Comano, Trentino, Italy) on patients aged $\leq 16$ years who underwent balneotherapy from April to October 2014. Patients with previous doctor-confirmed diagnosis of $\mathrm{AD}$ using the criteria of Hanifin and Rajka [11] were included in this study. As required by the principles of good clinical practice in thermal medicine and by the institute's policy [12], we considered any coexisting systemic pathology (e.g., infections, heart diseases, immunodeficiencies or malignancies) or cutaneous disease (e.g., viral, bacterial or fungal infections, skin cancer or ulcers) as exclusion criteria for the study. In fact, such pathologies make balneotherapy treatment inadvisable, as well. An informed, written consent was obtained from all parents/guardians before including the patients in the study.

During the admission visits to the Comano Thermal Spring Water Center, demographic and clinical data were collected through a physical exam and a doctor interview: $\mathrm{AD}$ severity, age of onset, history of $\mathrm{AD}$ in first-grade relatives, exposure to passive smoking, coexisting reported inhalant or food allergies. Treatments, including topical and systemic, used by patients in the previous month were recorded as well. AD severity was recorded during the admission visit using the following five SCORAD (SCORing Atopic Dermatitis) categories: $0-15,16-30,31-40,41-60$, > 60. SCORAD includes both objective items - percentage of the affected skin surface area (A; $0-100)$, intensity (B; $0-3$ points are assigned to each of the following elements: dryness, erythema, oozing/crusting, edema/papulation, excoriation, lichenification) - and subjective items ( $C$; $0-10$ points for each of the following elements: pruritus and sleeplessness). Individual item scores are then combined according to the following formula: $\mathrm{A} / 5+7 \mathrm{~B} / 2+\mathrm{C}$. The minimum and maximum SCORAD are therefore 0 and 103, respectively [13].

To describe the results from a statistical point of view, qualitative data were presented as frequency tables (number of observations or percentages) and/or through histograms, while quantitative data were expressed as number of observations, mean and standard deviation (SD). Chi-squared test with Yates correction was used to evaluate associations between AD severity (expressed through SCORAD categories) and qualitative variables. The differences were considered statistically significant with $p \leq 0.05$. Statistical data analysis was carried out using SAS software (SAS institute, Cary, North Carolina, United States of America).

\section{Results}

We recruited 867 patients whose mean age was $5.9 \pm 3.6$ years; $50.5 \%$ of them were females (Table 1 ).

The percentages of patients with SCORAD 0-15, 16$30,31-40,41-60$ and $>60$ were 41.2, 27.3, 16.3, 10.5 and $4.7 \%$ respectively. Thus, $41.2 \%$ of the patients had mild AD (SCORAD 0-15), 43.6\% had moderate AD (SCORAD 16-40) and $15.2 \%$ had severe AD (SCORAD > 40).

In $54.3 \%$ of the children, AD had first appeared before 6 months of age. Specifically, in $26.4 \%$ of them, the onset of $\mathrm{AD}$ had been reported before the age of 2 months, while in $27.9 \%$ it had been reported between the age of 2 and 6 months. $17.8 \%$ of the children were first affected by $\mathrm{AD}$ at the age of 7-12 months. A similar percentage of children (17.2\%) had developed AD at the age of 13 months- 3 years, while only $10.7 \%$ had developed AD after the age of 3 years. 
Table 1 Characteristics of the study population

\begin{tabular}{|c|c|}
\hline Characteristics $(n=867)$ & \\
\hline Age (years) & $5.9 \pm 3.6$ \\
\hline Females & $438(50.5 \%)$ \\
\hline \multicolumn{2}{|l|}{ SCORAD: } \\
\hline $0-15$ & $357(41.2 \%)$ \\
\hline $16-30$ & $237(27.3 \%)$ \\
\hline $31-40$ & $141(16.3 \%)$ \\
\hline $41-60$ & $91(10.5 \%)$ \\
\hline$>60$ & $41(4.7 \%)$ \\
\hline \multicolumn{2}{|l|}{ Age of onset } \\
\hline$<2$ months & $229(26.4 \%)$ \\
\hline $2-6$ months & $242(27.9 \%)$ \\
\hline 7-12 months & $154(17.8 \%)$ \\
\hline $13-36$ months & 149 (17.2\%) \\
\hline$>36$ months & $93(10.7 \%)$ \\
\hline History of $A D$ in first-grade relatives & $35(4.0 \%)$ \\
\hline Exposure to passive smoking & $134(15.5 \%)$ \\
\hline Reported inhalant allergy & 199 (23.0\%) \\
\hline Reported food allergy & $82(9.5 \%)$ \\
\hline \multicolumn{2}{|l|}{ Therapies in the last month: } \\
\hline Emollients & $478(55.1 \%)$ \\
\hline TCS & $396(45.7 \%)$ \\
\hline $1-5$ days/month & $120(13.8 \%)$ \\
\hline $6-10$ days/month & $116(13.4 \%)$ \\
\hline$>10$ days/month & $160(18.5 \%)$ \\
\hline $\mathrm{TCl}$ & $39(4.5 \%)$ \\
\hline Oral steroids & $55(6.3 \%)$ \\
\hline
\end{tabular}

Data were represented as $\mathrm{N}(\%)$ or mean \pm standard deviation $A D$ atopic dermatitis, SCORAD SCOring Atopic Dermatitis, $T C I$ topical calcineurin inhibitors TCS topical corticosteroids
A history of $\mathrm{AD}$ in first-grade relatives was reported in only $4.0 \%$ of the group, while coexisting reported inhalant or food allergies were recorded in $23.0 \%$ (mean age 7.9; $\mathrm{SD} \pm 2.6$ years) and $9.5 \%$ (mean age $5.8 ; \mathrm{SD} \pm 3.6$ years), respectively. Exposure to passive smoking was recorded in $15.5 \%$ of the patients.

A difference in the occurrence of reported food allergy was observed across the different $\mathrm{AD}$ severity categories $(p<0.0001$; Fig. 1$)$, ranging from $6.2 \%$ among patients with SCORAD $0-15$ to $31.7 \%$ in those with SCORAD > 60. No differences about the occurrence of passive smoking exposure and reported inhalant allergy were observed across the severity categories $(p=0.92$ and 0.15 , respectively; data not shown).

The AD treatments used in the previous month were, in order of frequency, as follows: emollients (55.1\%), TCS (45.7\%), oral steroids (6.3\%) and TCI (4.5\%). No systemic therapies other than oral corticosteroids were reported. The percentage of emollient users was slightly higher in patients with severe disease than in those with mild disease: $61.4 \%$ in those with severe $A D$ vs $59.0 \%$ (moderate AD) and 48.7\% (mild AD) $(p<0.01$, data not shown). No association between the use of emollients and TCS was observed (data not shown). Based on our data, $13.8 \%$ of the study population had applied TCS less than 5 days in the previous month and a similar percentage (13.4\%) in 6-10 days, whereas $18.5 \%$ had applied TCS more than 10 days (Table 1 ). Higher disease severity was associated with higher TCS use $(p<0.0001)$. For example, only $3.1 \%$ of patients with SCORAD $0-15$ had applied TCS more than 10 days in the previous month, the corresponding percentage in patients with SCORAD $>60$ being $75.6 \%$ (Fig. 2). Conversely, 79.8 and $10.4 \%$ of those with mild disease had used respectively no TCS or a 1-5 days TCS treatment in the preceding month, compared to 14.6 and $0.0 \%$ in patients with SCORAD $>60$. Among patients with severe AD, $36.6 \%$ had been treated

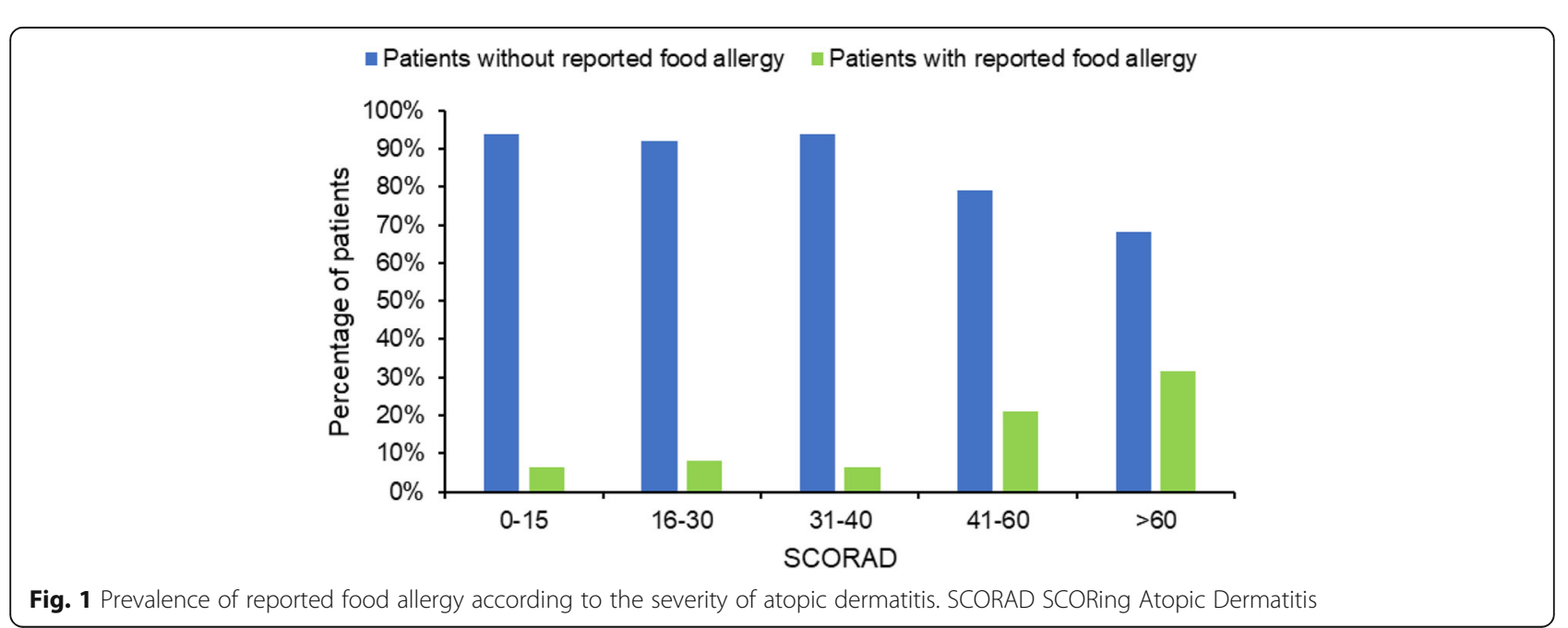




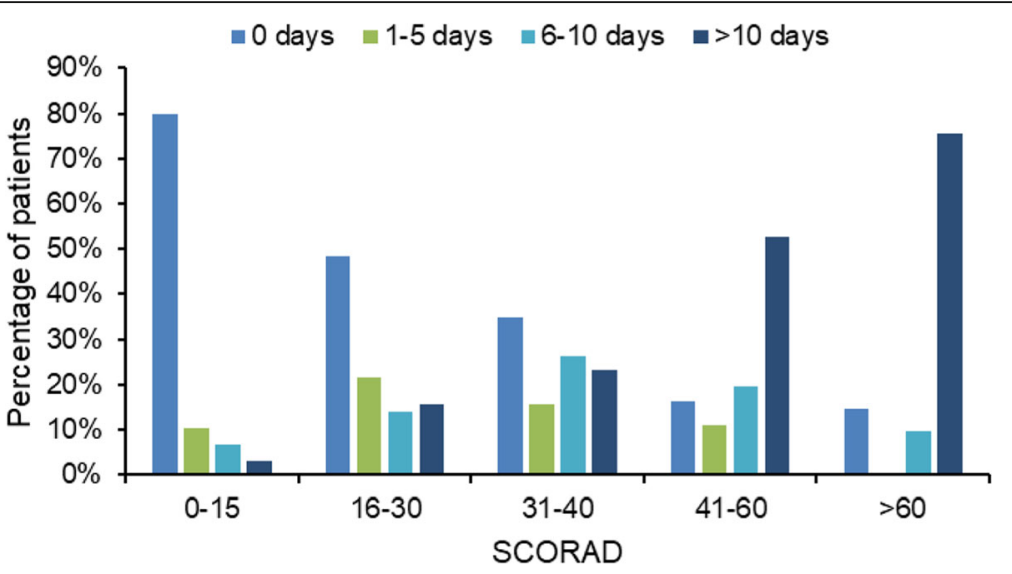

Fig. 2 Days of topical corticosteroids in the previous month according to the severity of atopic dermatitis. SCORAD SCORing Atopic Dermatitis

with systemic steroids in the previous month, $85.4 \%$ with TCS and $12.2 \%$ with TCI, while $9.8 \%$ had not used systemic steroids, TCS or TCI at all.

Moreover, $20.0 \%$ of the study population had followed elimination diets, although only $27.2 \%$ of those who were on elimination diets had a reported food allergy. On the contrary, $80.0 \%$ of the study population had not followed any elimination diets, although $5.0 \%$ of those who were not on elimination diets had a reported food allergy (Table 2).

\section{Discussion}

In our study, a significant difference in the occurrence of reported food allergy emerged across the different AD severity categories. This seems to confirm previous studies in which severe vs mild to moderate AD in children was associated with a higher one-year prevalence of food allergy (27.0\% vs $14.1 \%)$ [14]. Skin barrier defects play a pivotal role in the pathogenesis of $\mathrm{AD}$, and our findings mirror previously-published studies suggesting that skin barrier impairment, coupled with cutaneous allergen exposure, may be crucial in the development of food allergy and allergen sensitization through the skin (i.e., "dual-allergen exposure hypothesis") [15, 16]. Little evidence is currently available on the association between AD severity and passive smoking in children. In a study on 100 Greek children, parental passive smoking was associated with severe $A D$
(aOR: 4.6; 95\% CI: 1.0-22.1; $p=0.050$ ). However, a weaker association with severe $\mathrm{AD}$ was found, if compared to the other risk factors evaluated (excessive cleanliness $p<0.001$, aOR: 59.4; 95\% CI: 10.9-322.6; Radioallergosorbent Test, RAST $>0.7 \mathrm{kU} / 1 p=0.014$, aOR: 7.9; 95\% CI: 1.5-41.0) [17]. In our study, no differences in the occurrence of passive smoking exposure and reported inhalant allergy were found across the $\mathrm{AD}$ severity categories $(p=0.92$ and 0.15 , respectively).

As for the treatment patterns, 9.8\% of patients with severe AD had not been treated with TCS, TCI or any systemic steroids in the previous month. Such a figure underlines the magnitude of undertreatment among patients with severe $\mathrm{AD}$, at least in those attending the Comano Thermal Spring Water Center. In a country like Italy, where the National Health System guarantees free unlimited access to pediatric primary care, AD undertreatment might largely be explained by limited access to medical care due to personal beliefs (e.g., seeking alternative treatments) or by low adherence (due to "corticophobia", forgetfulness or other reasons). Additionally, $36.6 \%$ of patients with severe AD had been treated with systemic steroids in the previous month. Interestingly, although short courses of systemic steroids are an effective and inexpensive treatment, the latest European and Italian guidelines on the management of $\mathrm{AD}$ recommend a limited use because of their unfavorable risk-benefit

Table 2 Use of elimination diets according to reported food allergy

\begin{tabular}{llll}
\hline Elimination diets & Patients without reported food allergy & Patients with reported food allergy & Total \\
\hline No & $659(95.0 \%)$ & $35(5.0 \%)$ & $694(80.0 \%)$ \\
Yes & $126(72.8 \%)$ & $47(27.2 \%)$ & $173(20.0 \%)$ \\
Total & $785(90.5 \%)$ & $82(9.5 \%)$ & $867(100.0 \%)$ \\
\hline
\end{tabular}

Data were represented as $\mathrm{N}(\%)$ 
ratio. Moreover, it is stated there that the indication for oral steroids in children should be handled even more cautiously than in adults $[3,10,18-20]$. It is also worth noting the limited use of emollients in our study population: only $55.1 \%$ of patients resorted to them in the previous month, their occurrence being slightly higher in patients with severe disease. Few studies have reported the prevalence in the use of emollients in pediatric patients with AD. A Polish study [21] has showed a prevalence of emollients use of $82 \%$ in AD patients. Still, the small study population (22 patients, adults and children) makes it difficult to generalize these findings. It is important to point out that emollients are an essential element in the treatment of AD. In fact, in several studies, regular use of emollients has proved to achieve a short-term steroid sparing effect in mild to moderate $\mathrm{AD}$ [22] and long-term use of emollients is recommended for the maintenance of stable disease in the latest European and Italian guidelines [3, 18-20]. Health economic analyses showed that the use of emollients is cost-effective compared with a no-treatment strategy [23]. Several factors may explain our findings. First, as the Italian National Health System does not cover emollients, their cost could represent a hindrance to their use. Secondly, parents' poor knowledge on the long-term efficacy of emollients in preventing AD flare-ups may also lead to underuse. Indeed, a recent interview study [24] showed that parents had mixed views on long-term emollient use to prevent exacerbations. The authors concluded that providing a rationale for long-term emollient use could help improve adherence. Educational programs and adequate time to allow for patient education during routine visits may also help raise awareness about the utility of emollients in managing AD.

Finally, it is interesting to point out in our study how surprisingly only $27.2 \%$ of patients on elimination diets had a reported food allergy. It is also interesting to highlight how $5.0 \%$ of patients who were not on elimination diets in our study had a reported food allergy. While elimination diets are indeed critical in AD patients with food allergy, it seems fundamental for pediatricians and dermatologists to promote an evidence-based management of suspected adverse reactions to food [25-27] based on a rigorous diagnostic allergy work-up carried out according to the current guidelines [28]. Indeed, an incorrect management of food allergy can lead to inappropriate and dangerous dietary restrictions - especially in children, who are very vulnerable to nutritional deficiencies [29] or to the risk of reactions [30-32].

The main limitations of our study are mostly due to the clinical setting in which it was carried out, i.e., admission visits for balneotherapy. Indeed, the characteristics and treatment patterns in pediatric AD cases recorded at the Comano Thermal Spring Water Center may not be entirely representative of the general Italian pediatric population. Moreover, food and inhalant allergy was reported, but no rigorous diagnostic allergy work-up (based on the use of prick test, specific IgE or food challenge) nor other laboratory investigations were performed at the Comano Thermal Spring Water Center, which is not the appropriate clinical setting to carry them out. Lastly, data on antihistamine use were not collected. However, the large population size is undoubtedly the strongest point of our study, as it enabled us to describe the characteristics and treatment patterns in pediatric AD cases.

\section{Conclusions}

A significant difference in the prevalence of reported food allergy emerged across the different AD severity categories. Furthermore, although further data remain necessary to confirm our preliminary findings, undertreatment in children with AD was observed - at least in patients attending the Comano Thermal Spring Water Center. Moreover, many patients followed elimination diets in the absence of reported food allergy.

\section{Abbreviations \\ AD: Atopic Dermatitis; Cl: Confidence Interval; OR: Odds Ratio; RAST: Radioallergosorbent Test; SCORAD: SCORing Atopic Dermatitis; SD: Standard Deviation; TCS: Topical Corticosteroids; TCI: Topical Calcineurin Inhibitors}

\section{Acknowledgements}

Not applicable.

\section{Authors' contributions}

DG and MG analyzed the data, drafted the initial manuscript and reviewed the manuscript. GB conceptualized, designed the work and collected the data. RP analyzed the data, drafted the initial manuscript and reviewed the manuscript. MP, FM, EN and GG reviewed the manuscript. MC and EB conceptualized, designed the work and reviewed the manuscript. All authors approved the final manuscript as submitted and agreed to be accountable for all aspects of the work.

\section{Funding}

This research did not receive any specific grant from funding agencies in the public, commercial, or not-for-profit sectors. Professional English language proofreading was financed by the "Giovan Battista Mattei" Research Institute, as well as the publication fee. However, no significant funding source could have influenced the outcomes of this work.

\section{Availability of data and materials}

The access to datasets generated and/or analyzed during the current study is not publicly available due to the Center's research policy to guarantee the privacy of the participants, whose research data are confidential. Aggregate analyses are however available on reasonable request to the corresponding author.

\section{Ethics approval and consent to participate}

An informed, written consent was obtained from all parents/guardians prior to including the patients in the study. The study was reviewed and

approved by the board of the "Giovan Battista Mattei" Research Institute.

Consent for publication

Not applicable. 


\section{Competing interests}

The authors declare that they have the following competing interests to disclose in relation to this paper: DG worked as a consultant doctor at Azienda Consorziale Terme di Comano from May to September 2016. MG worked as a consultant doctor at Azienda Consorziale Terme di Comano from April to October 2015. GB worked as a consultant doctor at Azienda Consorziale Terme di Comano from April to October 2014. RP, MP, FM and EN have no competing interests to disclose in relation to this paper. GG served as a consultant for Azienda Consorziale Terme di Comano. MC is the president of the "Giovan Battista Mattei" Research Institute. EB is a member of the scientific committee of the "Giovan Battista Mattei" Research Institute. However, no significant competing interest could have influenced the outcomes of this work.

\section{Author details}

'Department of Medicine, Section of Dermatology and Venerology, University of Verona, Verona, Italy. ${ }^{2}$ Allergy Unit, Department of Pediatrics,

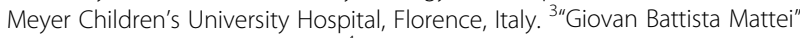
Research Institute, Stenico, Italy. ${ }^{4}$ Department of Clinical and Evaluative Epidemiology, Trento Health Service, Trento, Italy. ${ }^{5}$ Department of Pediatrics, S. Maria del Carmine Hospital, Rovereto, Italy.

Received: 17 March 2020 Accepted: 2 February 2021 Published online: 16 April 2021

\section{References}

1. Deckers IA, McLean $S$, Linssen $S$, et al. Investigating international time trends in the incidence and prevalence of atopic eczema 1990-2010: a systematic review of epidemiological studies. PLoS One. 2012;7:e39803.

2. Drucker AM, Wang AR, Li WQ, et al. The burden of atopic dermatitis: summary of a report for the National Eczema Association. J Invest Dermatol. 2017;137(1):26-30.

3. Damiani G, Calzavara-Pinton P, Stingeni L, et al. Italian guidelines for therapy of atopic dermatitis-adapted from consensus-based European guidelines for treatment of atopic eczema (atopic dermatitis). Dermatol Ther. 2019;32(6): e13121.

4. Cork MJ, Britton J, Butler L, et al. Comparison of parent knowledge, therapy utilization and severity of atopic eczema before and after explanation and demonstration of topical therapies by a specialist dermatology nurse. $\mathrm{Br} J$ Dermatol. 2003;149:582-9.

5. Krejci-Manwaring J, Tusa MG, Carroll C, et al. Stealth monitoring of adherence to topical medication: adherence is very poor in children with atopic dermatitis. J Am Acad Dermatol. 2007;56:211-6.

6. Brown KL, Krejci-Manwaring J, Tusa MG, et al. Poor compliance with topical corticosteroids for atopic dermatitis despite severe disease. Dermatol Online J. 2008;14:13.

7. Li AW, Yin ES, Antaya RJ. Topical corticosteroid phobia in atopic dermatitis: a systematic review. JAMA Dermatol. 2017;153:1036-42.

8. Charman CR, Morris AD, Williams HC. Topical corticosteroid phobia in patients with atopic eczema. Br J Dermatol. 2000;142:5.

9. Hon KL, Kam WY, Leung TF, et al. Steroid fears in children with eczema. Acta Paediatr. 2006:95:1451-5.

10. Drucker AM, Eyerich $\mathrm{K}$, de Bruin-Weller MS, et al. Use of systemic corticosteroids for atopic dermatitis: international eczema council consensus statement. Br J Dermatol. 2018;178:768-75.

11. Hanifin JM, Rajka G. Disgnostic features of atopic dermatitis. Acta Derm Venereol Suppl. 1980;92:44-7.

12. Giovannini M, Geat D, Barlocco G, et al. A caregiver-reported global severity assessment in pediatric atopic eczema: the Comano score. Ital I Pediatr. 2020;46(1):50

13. Severity scoring of atopic dermatitis: the SCORAD index. Consensus report of the European task force on atopic dermatitis. Dermatology. 1993;186(1): 23-31.

14. Silverberg الJ, Simpson EL. Association between severe eczema in children and multiple comorbid conditions and increased healthcare utilization. Pediatr Allergy Immunol. 2013;24(5):476-86.

15. Du Toit G, Sampson HA, Plaut M, et al. Food allergy: update on prevention and tolerance. J Allergy Clin Immunol. 2018;141(1):30-40.

16. Logan $\mathrm{K}$, Du Toit G, Giovannini M, et al. Pediatric allergic diseases, food allergy, and oral tolerance. Annu Rev Cell Dev Biol. 2020;36:511-28.
17. Fotopoulou M, lordanidou M, Vasileiou E, et al. A short period of breastfeeding in infancy, excessive house cleaning, absence of older sibling, and passive smoking are related to more severe atopic dermatitis in children. Eur J Dermatol. 2018;28:56-63.

18. Galli E, Neri I, Ricci G, et al. Consensus conference on clinical management of pediatric atopic dermatitis. Ital J Pediatr. 2016;42:26.

19. Wollenberg A, Barbarot S, Bieber T, et al. Consensus-based European guidelines for treatment of atopic eczema (atopic dermatitis) in adults and children: part I. J Eur Acad Dermatol Venereol. 2018;32:657-82.

20. Wollenberg A, Barbarot S, Bieber T, et al. Consensus-based European guidelines for treatment of atopic eczema (atopic dermatitis) in adults and children: part II. J Eur Acad Dermatol Venereol. 2018;32:850-78.

21. Basałygol M, Zegarska B, Czajkowski R. The influence on skin care of the use of emollients for skin lesions during the course of atopic dermatitis. Folia Medica Copernicana. 2013:1:62-6.

22. Grimalt R, Mengeaud V, Cambazard F, Study Investigators Group. The steroid-sparing effect of an emollient therapy in infants with atopic dermatitis: a randomized controlled study. Dermatology. 2007;214:61-7.

23. Hjalte F, Asseburg C, Tennvall GR. Cost-effectiveness of a barrierstrengthening moisturizing cream as maintenance therapy vs. no treatment after an initial steroid course in patients with atopic dermatitis in Sweden with model applications for Denmark, Norway and Finland. J Eur Acad Dermatol Venereol. 2010;24:474-80.

24. Santer M, Muller I, Yardley L, et al. Parents' and carers' views about emollients for childhood eczema: qualitative interview study. BMJ Open. 2016:6:e011887.

25. Barni S, Liccioli G, Sarti L, et al. Immunoglobulin E (IgE)-mediated food allergy in children: epidemiology, pathogenesis, diagnosis, prevention, and management. Medicina (Kaunas). 2020;56(3):111.

26. Foong RX, Giovannini M, du Toit G. Food-dependent exercise-induced anaphylaxis. Curr Opin Allergy Clin Immunol. 2019;19(3):224-8.

27. Harrison FC, Giovannini M, Kalaichandran A, et al. Food allergy: eLS, John Wiley \& Sons, Ltd; 2020. https://doi.org/10.1002/9780470015902.a0028380.

28. Muraro A, Werfel T, Hoffman-Sommergruber $\mathrm{K}$, et al. EEACl food allergy and anaphylaxis guidelines: diagnosis and management of food allergy. Allergy. 2014;69:1008-25.

29. Mori F, Serranti D, Barni S, et al. A kwashiorkor case due to the use of an exclusive rice milk diet to treat atopic dermatitis. Nutr J. 2015;14(1):83.

30. Mehta $\mathrm{H}$, Groetch $\mathrm{M}$, Wang J. Growth and nutritional concerns in children with food allergy. Curr Opin Allergy Clin Immunol. 2013;13:275-9.

31. Blom WM, Michelsen-Huisman AD, van Os-Medendorp $H$, et al. Accidental food allergy reactions: products and undeclared ingredients. J Allergy Clin Immunol. 2018;142:865-75.

32. Barni S, Mori F, Giovannini M, et al. In situ simulation in the management of anaphylaxis in a pediatric emergency department. Intern Emerg Med. 2019; 14:127-32.

\section{Publisher's Note}

Springer Nature remains neutral with regard to jurisdictional claims in published maps and institutional affiliations.

Ready to submit your research? Choose BMC and benefit from:

- fast, convenient online submission

- thorough peer review by experienced researchers in your field

- rapid publication on acceptance

- support for research data, including large and complex data types

- gold Open Access which fosters wider collaboration and increased citations

- maximum visibility for your research: over $100 \mathrm{M}$ website views per year

At $\mathrm{BMC}$, research is always in progress.

Learn more biomedcentral.com/submissions 